

CHALMERS

UNIVERSITY OF TECHNOLOGY

\title{
Using quantitative microbial risk assessment and life cycle assessment to assess management options in urban water and sanitation infrastructures:
}

Downloaded from: https://research.chalmers.se, 2023-04-26 09:40 UTC

Citation for the original published paper (version of record):

Harder, R., Peters, G., Ashbolt, N. et al (2017). Using quantitative microbial risk assessment and life cycle assessment to assess management options in urban water and sanitation infrastructures: Opportunities and unresolved issues. Microbial Risk Analysis, 5: 71-77. http://dx.doi.org/10.1016/j.mran.2016.11.004

N.B. When citing this work, cite the original published paper. 
4 Using quantitative microbial risk assessment and life cycle assessment to assess management options in urban water and sanitation infrastructures: Opportunities and unresolved issues

7 Robin Harder, ${ }^{\mathrm{a},{ }^{*}}$, Gregory M. Peters ${ }^{\mathrm{a}}$, Nicholas J. Ashbolt ${ }^{\mathrm{b}}$, Magdalena Svanströma

${ }^{a}$ Chemical Environmental Science, Department of Chemistry and Chemical Engineering, Chalmers University of Technology, 41296 Gothenburg, Sweden

${ }^{\mathrm{b}}$ School of Public Health, University of Alberta, Edmonton, Alberta T6G 2G7, Canada

E-Mail: robin.harder@wetryharder.ch (Robin Harder, corresponding author), petersg@chalmers.se (Gregory Peters), ashbolt@ualberta.ca (Nicholas Ashbolt),magdalena.svanstrom@chalmers.se (Magdalena Svanström)

\section{Abstract}

Quantitative microbial risk assessment (QMRA) and life cycle assessment (LCA) are two distinct environmental management techniques that can provide complementary perspectives when assessing management options for urban water and sanitation infrastructure. While QMRA per definition concerns microbial risks, accounting for pathogens in LCA has received little attention. A few case studies, however, have explored the concurrent use of QMRA and LCA. These studies were motivated by the perceived need to address trade-offs between local health burdens associated with pathogens and global health burdens associated with other stressors at different spatial and temporal scales. Along with the LCA, the QMRA results were sought to provide the basis for addressing such trade-offs, rather than for deciding whether pathogen-related adverse effects experienced by specific individuals or populations are acceptable, or which scenario leads to the highest overall health burden for a given community, as is traditionally the case in QMRA. This paper highlights opportunities and unresolved issues related to the concurrent use of QMRA and LCA, such as assumptions in translating chemical and pathogen health impacts to a common metric or other mode structure and parameterisation aspects. Our aim is to facilitate more consistent design and transparent communication of future case studies of this type, and to highlight opportunities for QMRA experts to contribute to LCA method development so as to include pathogen health impacts. While most examples provided in this paper focus on water reuse, the findings apply more broadly and can also be extrapolated to other pathogen exposures in the context of urban water and sanitation systems as well as other contexts.

Keywords: LCA, QMRA, human health risks, pathogen risk, pathogen impact, trade-off 
Quantitative microbial risk assessment (QMRA) and life cycle assessment (LCA) are among the environmental management techniques used to support decision-making regarding urban water and sanitation systems, including water reuse (Xue et al. 2015). QMRA offers a structured approach to assess human health risks that arise from the exposure to pathogens. QMRA models describe the cause-effect chain starting from the pathogen sources and ending with the adverse effects of pathogen exposures on human health. The application of QMRA is commonplace in the assessment of urban water and sanitation systems (e.g. Amha et al. 2015, Liu and Persson 2014, Sales-Ortells and Medema 2015, Schoen et al. 2014, Symonds et al. 2014, Xue et al. 2016). LCA offers a structured approach to assess the potential environmental impacts of products (i.e. goods and services), where the unit of analysis is the life cycle, or supply chain, of the product under consideration. Life cycle impact assessment (LCIA) models describe cause-effect chains starting from resource use and emissions and ending with potential impacts on various areas of protection (i.e. human health, natural environment, and natural resources). Also LCA has been used extensively to assess urban water and sanitation systems, amongst others for water reuse (e.g. García-Montoya et al. 2015, Hendrickson et al. 2015). While QMRA per definition concerns microbial risks, the adverse effects of pathogens on human health are not routinely included in LCA, as no standard LCIA methodology for pathogen impact potential is currently available. A few case studies (Aramaki et al. 2006, Harder et al. 2014, Heimersson et al. 2014, Kobayashi et al. 2015a), however, have explored the concurrent use of QMRA and LCA to assess management options for urban water and sanitation infrastructures in terms of the broader adverse effects of pathogens and other stressors on human health and the environment. The main purpose of this article is to highlight and discuss opportunities and unresolved issues related to assessing management options for urban water and sanitation systems in terms of the broader adverse effects of pathogens and other stressors on human health and the environment through concurrent use of QMRA and LCA. But first, we briefly introduce LCA and QMRA at the conceptual level, and provide a summary and analysis of the studies that explored the concurrent use of QMRA and LCA and that were reported in peer-reviewed scientific journals.

\section{Background}

LCA is a technique for the environmental assessment of products (i.e. goods or services) and generally covers the entire life cycle of a product, from raw material and natural resource acquisition to final disposal. It is also referred to as environmental LCA in order to distinguish it from social LCA and life cycle costing (LCC). The procedure of performing an environmental LCA is described in the ISO standards 14040:2006 and 14044:2006. These ISO standards describe LCA as a compilation and evaluation of the inputs, outputs and potential environmental impacts of a product system. A product system hereby is a collection of processes (i.e. activities transforming flows of material and energy) that models the life cycle of a product and performs one or more defined functions. A key feature of LCA is the functional unit. It represents a quantification of the identified function(s) of the studied product system and serves as a reference to which the inputs, outputs and potential environmental impacts can be related. For example, the functional unit for water reuse scenarios could be the provision of $1 \mathrm{~m}^{3}$ of non- 
According to the ISO standards, LCA consists of four stages, which interact with one another in an iterative manner. Goal and scope definition is concerned with stating the intended application of the LCA study, the reason for carrying it out, to whom and how the results are to be communicated, as well as a number of important modelling specifications including the functional unit, the system boundaries, cut-off criteria, allocation principles (i.e. how to partition the input and output flows of processes between the product under study and co-products), and which options to model. Life cycle inventory analysis (LCI) is concerned with quantifying the environmentally relevant resource use and emissions associated with a product system in relation to the selected functional unit. Life cycle impact assessment (LCIA) is concerned with translating the resource use and emissions estimated in the LCI into potential environmental impacts, also in relation to the selected functional unit. Since its emergence in the late 1970s, LCA methodology has developed considerably and several life cycle inventory (LCI) databases and LCIA methods are available (Baumann and Tillman 2004). LCIA methods cover a continuously expanding number of impact categories and corresponding characterisation models for the conversion of the resource use and emissions from a product system into potential environmental impacts (Hauschild et al. 2013). Common impact categories used in LCIA include global warming, acidification, human toxicity, land use, eutrophication, water use, land use, abiotic resource depletion, and many more. The models used to describe these impacts in LCA may be at a "midpoint" level (e.g. greenhouse gas emissions enumerated as $\mathrm{kg}$ of $\mathrm{CO}_{2}$ equivalents) or a more meaningful but less accurate "endpoint" level (e.g. climate change impacts on human health estimated in disability-adjusted life years). Disability-adjusted life years (DALY) are a measure of overall disease burden that was developed in the 1990s (Murray 1994). A recent discussion of the concept is provided in Gao et al. (2015). Life cycle interpretation is concerned with interpreting the results in order to draw conclusions and is done in between all stages. Figure 1 provides a visual summary of LCA. Two broad types of LCA are attributional and consequential LCA. Attributional LCA describes the environmentally relevant resource use and emissions related to a given product, while consequential LCA describes how the environmentally relevant resource use and emissions will change in response to possible decisions (Finnveden et al. 2009).

\section{QMRA}

QMRA is a technique to evaluate the effects on human health resulting from the exposure to representative pathogen members, typically addressing viral, bacterial and protozoan members (known as reference pathogens). Two broad types of QMRA commonly distinguished are static and dynamic QMRA. In static QMRA the exposure of individual hosts to reference pathogen(s) through one or multiple exposure pathways is modelled without accounting for immunity and the secondary spreading of disease. Dynamic QMRA models take into account immunity and the secondary spreading of disease from person-to-person (Eisenberg et al. 2002, Eisenberg et al. 2004, Eisenberg et al. 2008, Soller 2009), and recently also include zoonotic (i.e. animals-to-human) spreading (Waters et al. 2016). Either static or dynamic QMRA models may also be undertaken with point estimates (deterministic) or with distributional (stochastic) parameter values (Medema et al. 2006). In this paper, we focus primarily on static QMRA.

In static QMRA, an obvious assessment endpoint is the single-event probability of infection ( $\mathrm{P}_{\text {inf,event }}$ ) or illness

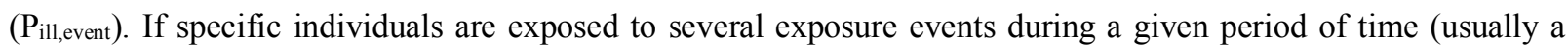
year), it is possible to have the annual probability of infection ( $\left.\mathrm{P}_{\text {inf,year }}\right)$ or illness ( $\left.\mathrm{P}_{\text {ill,year }}\right)$ associated with multiple exposure events as assessment endpoint. Another possible assessment endpoint would be the number of cases of 
infection or illness per event or year ( $\left.\mathrm{N}_{\text {inffill,eventyear }}\right)$. This assessment endpoint follows directly from the probability of infection or illness per event or year through multiplication by the number of individuals exposed. Single-event as well as annual probabilities or number of cases of infection or illness can be compared (separately) with corresponding threshold risk values considered acceptable by the regulators/stakeholders. For example, a given QMRA study might address dermal exposure of agricultural workers during irrigation (Al-Jassim et al. 2015), or the ingestion of irrigation water by farmers or children playing in fields irrigated with reused water (Symonds et al. 2014). Different exposures (i.e. combination of the reference pathogen, the suite of exposure pathways, and the host) may lead to similar health outcomes (e.g. a certain type of illness). In this case, it is possible to compare different exposures and identify those with the largest human health impact. When different exposures lead to different health outcomes, however, comparison and prioritisation would require weighting or severity factors for each distinct health outcome. The increasing availability of severity factors (e.g. Havelaar and Melse 2003, Havelaar et al. 2003, Kemmeren et al. 2006, Vijgen et al. 2007) enables the translation of a probability or number of cases of infection or illness into a health burden (also referred to as burden of disease), often expressed as DALY. Also health burdens can be compared with corresponding threshold values considered acceptable, such as an annual target of one DALY per million as used by WHO (WHO 2006). Furthermore, health burdens allow for comparison and prioritisation among hazard exposures with different health outcomes. Also, the aggregation of health burdens related to different exposures becomes possible and meaningful. For instance, several QMRA studies estimated the health burden related to a suite of reference pathogen exposures with water reuse (e.g. Ayuso-Gabella et al. 2011, Barker et al. 2013a, Barker et al. 2013b, Chen et al. 2012, Forslund et al. 2010, Hamilton et al. 2007) or other water and sanitation systems (e.g. Katukiza et al. 2014, Schoen et al. 2014). In these studies, the focus of the assessment shifted from the acceptability of individual exposures towards the overall community impact associated with a suite of exposures associated with a given management option. Table 1 illustrates which assessment endpoints are meaningful in combination with certain assessment purposes.

\section{Model structure of static QMRA}

Beaudequin et al. (2015) proposed a conceptual model for the assessment of health risks associated with pathogens in diverse water reuse scenarios through static QMRA. Here we draw on their work and extend it with a particular emphasis on facilitating the subsequent discussion of concurrent use of QMRA and LCA. Following Beaudequin et al. (2015), we distinguish four sub-models. The technical system sub-model (a generalisation of the "pond operation and performance sub-model" of Beaudequin et al. 2015) takes into account key influences on the concentration of pathogens in the water reuse scenarios under consideration. The exposure sub-model describes the interactions between the reference pathogens and the environment (i.e. environmental fate and transport between the point of emission and the point of exposure of the host), and between the hosts and the environment (i.e. exposure route, exposure medium, exposure frequency, and exposure volume). The dose-response sub-model represents the interaction between each reference pathogen and the host. Both pathogen characteristics and host characteristics influence the response to a given pathogen dose and there is considerable variability regarding both sets of characteristics. However, various host effects are generally not accounted for, such as host immunological status or microbiome, both key determinants in pathogenicity (Hajishengallis et al. 2012, Havelaar et al. 2014, Karlsson et al. 2014). The risk characterisation sub-model estimates a number of cases of infection or illness, or a 
health burden in terms of DALYs based on the probability of infection or illness obtained through the doseresponse sub-model. The four sub-models and the relationships among them are visualised in Figure 2.

Regardless of the assessment endpoint and purpose, the assessment requires information about the emissions of pathogens, their fate and transport in the environment, the exposure of different host groups to the pathogens, as well as the effects of the pathogens on the hosts. The respective model parameters may vary as there is often a range of operating and exposure conditions, pathogen and host characteristics, and courses of disease that are possibly relevant. Every technical system scenario (e.g. a certain set of operating conditions) related to a given water reuse scenario in principle gives rise to multiple exposure scenarios (i.e. a suite of exposures that each can be parameterised in different ways). For every combination of technical system scenario and exposure scenario, the appropriate (suite of) dose-response sub-model and risk characterisation sub-model should be chosen. Hereby, particular consideration may be given to sensitive or otherwise unique life-stages (e.g. pregnant women, young children, elderly people, other immunocompromised individuals) (Beaudequin et al. 2015). Sensitive or otherwise distinct people may not only be more susceptible to an initial infection (thus requiring a different parameterisation of the dose-response sub-model), but may also be more likely to become symptomatic (thus requiring a different parameterisation of the risk characterisation sub-model). However, only a limited number of dose-response relationships have been developed and published (Beaudequin et al. 2015). This means that one simply has to do with the limited number of available dose-response relationships and document these limitations. All-in-all, accounting for the effect of pathogens in urban water and sanitation systems in principle would require consideration of a suite of QMRA model variants (see also Figure 2), akin to previous screening-level risk assessments (e.g. Sales-Ortells and Medema 2014). Each model variant thereby reflects a specific parameterisation of the technical system, exposure, dose-response, and risk characterisation sub-models. Strictly speaking, all possible model variants would need to be considered in the assessment. This is not practical, however, and only a limited number of model variants can realistically be considered (e.g. Petterson and Stenström 2015).

\section{Studies that have explored the concurrent use of QMRA and LCA}

A search in the Scopus database (TITLE-ABS-KEY (QMRA OR "microbial risk assessment" OR "microbial risk*" OR "pathogen risk*") AND TITLE-ABS-KEY (LCA OR "life cycle assessment" OR "life-cycle assessment" OR "lifecycle assessment")) in December 2015 yielded three case studies investigating the concurrent use of QMRA and LCA. These studies were motivated by the perceived need to address trade-offs between local health burdens associated with pathogens and global health burdens associated with other stressors at different locations and points in time.

Aramaki et al. (2006) contrasted the reduction of adverse health effects related to pathogen inactivation resulting from the installation of an urban wastewater system (estimated based on QMRA) with the increase in adverse health effects associated with other stressors resulting from construction and operation of the treatment plant (estimated based on LCA). Although the QMRA results were directly compared to the LCA results, the QMRA results were not presented as an LCA impact category. Harder et al. (2014) and Heimersson et al. (2014) (one study reported in two parts) sought to account for adverse effects of pathogens in LCA of wastewater management scenarios in order to compare the adverse effects of pathogens on human health and other adverse effects on human health for two wastewater management scenarios. Hereby, the pathogen-related effects were 
estimated based on QMRA (Harder et al. 2014) and the results were presented as an LCA impact category alongside other impact categories based on LCIA models (Heimersson et al. 2014). Kobayashi et al. (2015a) investigated a scenario where recycled water from a municipal wastewater treatment plant was used to replace water released from a dam to maintain environmental flows in a nearby river. To this end, the yearly health burden associated with the consumption of treated river water and recreational use of the river with and without implementation of the large-scale water recycling project was estimated. The health burden associated with pathogens (estimated based on QMRA) was then compared with human health impacts resulting from the operation of the water recycling scheme and associated with stressors other than pathogens (estimated through LCA). This comparison was intended to reveal trade-off relationships between local impacts (i.e. pathogen-related effects estimated based on QMRA) and global impacts (i.e. other adverse effects on human health estimated through LCA). The overall model structure is strikingly similar in the above three studies. Basically, QMRA was used to estimate the pathogen-related health burden for a number of core processes, while LCA was used to estimate the health burden related to other stressors for both the core processes and the supply-chain processes (see Figure 3).

In the study by Aramaki et al. (2006), the pathogen-related health burden estimated based on QMRA represents aggregate effects for the downstream community as a whole. In the study by Harder et al. (2014) and Heimersson et al. (2014), the pathogen-related health burden estimated based on QMRA represents the aggregate health burden for all people possibly exposed to pathogens as a direct result of wastewater management operations (but not supply-chain processes). In the study by Kobayashi et al. (2015a), the pathogen-related health burden estimated based on QMRA represents the aggregate health burden for all people possibly exposed to pathogens through consumption of river water and recreational use of the river. Comparing and contrasting QMRA results with LCA results is possible because the concept of DALY has been adopted in both QMRA and LCA. It was recommended in the literature, however, that understanding the background information on how DALYs are derived is crucial to ensure the consistency of DALYs used in quantitative risk assessment (QRA) and LCA (Kobayashi et al. 2015b). Finally, it should be noted that the case studies that have explored the concurrent use of QMRA and LCA all relied on static QMRA and attributional LCA.

\section{Opportunities and issues related to concurrent use of QMRA and LCA}

The recent efforts to look into trade-off relationships between pathogen-related and other impacts on human health in the context of urban water and sanitation systems that are considered in this paper illustrate new opportunities for the use of QMRA - amongst others for the assessment of water reuse. Not only can QMRA provide the basis for deciding whether pathogen-related adverse effects experienced by specific individuals or populations are acceptable, or which management option leads to the highest overall health burden for specific individuals or populations - concurrent use of QMRA and LCA can also provide a basis for avoiding problem shifting between pathogen-related and other health burdens. For example, if two water reuse options with different levels of disinfection were considered, it would be possible to investigate whether the reduction of the local health burden associated with pathogens might be offset by an increase of the global health burden associated with the operation of the disinfection process. In the remainder of this paper, we discuss a number of issues to be aware of with regard to concurrent use of QMRA and LCA. 
When the purpose of a QMRA model is to provide comparison with a target risk level, it is important to identify the model parameterisations that impact the most on specific individuals, generally via some form of sensitivity analysis (e.g. Petterson et al. 2007). When the purpose of a QMRA model is to compare different management options, or to avoid problem shifting between pathogen-related and other health burdens, however, it is important to identify those model parameterisations that contribute most to the overall impact aggregated over all possible exposures, which means that the likelihood (distribution) of each parameter needs to be known or estimated (stochastic QMRA). The most sensitive model parameters may differ between the two cases as a model parameterisation with a lower health risk on a per individual basis may still lead to a higher impact on a population basis if a larger number of individuals are affected.

LCA typically considers routine operations under steady-state conditions when the technical systems operate according to the design specifications. Such practice is perfectly sensible when it can be assumed that routine operations indeed are responsible for the larger part of the impacts. In QMRA, as pathogens generally represent acute effects (one gets infected or not by one exposure), it is important to take into consideration seasonal variations and periods of non-routine operation (e.g. rain events, treatment upsets or sub-optimal performance) (Beaudequin et al. 2015, Nilsson et al. 2007, Signor et al. 2007). This means that, also when QMRA results are to be compared to LCA results, it might be appropriate to consider modelling not only routine operations (as typical for LCA) but to also account for hazardous event periods that may occur, despite the inconsistency that may be introduced if impact categories considered in LCA are estimated based on LCIA models accounting for routine operation scenarios only. Such inconsistency is warranted if short-duration events that may occur on relatively infrequent intervals dominate pathogen risks (e.g. Medema et al. 2006), while for other scenarios (generally well operated drinking water plants) routine operations may still present the largest impacts (e.g. Westrell et al. 2003).

When there is an existing QMRA study that was designed to support threshold comparisons, it may be tempting to convert the single-event or annual probabilities or numbers of cases of infection or illness into health burdens for subsequent aggregation and comparison with LCA results (as is the case for some exposures in Harder et al. 2014). Such practice could be problematic as the parameterisation of the original QMRA may not be according to what would make most sense for a QMRA that is designed explicitly to produce results that are used alongside LCA results.

\section{Choice of dose-response relationships}

In QMRA models, dose-response relationships are usually non-linear. As dose-response relationships in LCIA usually are linear, an obvious question is whether dose-response relationships in QMRA could be linearized in the case where QMRA results are to be compared with LCA results (Harder et al. 2016). The application of linear dose-response relationships in LCIA models for human toxicity of chemicals, for instance, is acceptable because the assessment is concerned with chronic effects and the doses considered in a given LCA study usually are on the lower end of the dose-response curve. The assessment of adverse effects of pathogens on human health, however, is mostly concerned with acute effects, and the doses a given host is exposed to can be further up the the doseresponse curve (Harder et al. 2016). It is therefore generally not recommended to linearize dose-response relationships for pathogens in QMRA models, not even when the results are to be compared with LCA results (see also Harder et al. 2016). 
Another important aspect regarding the choice of dose-response relationship is that some dose-response relationships that have been shown to be inappropriate are still in use in the literature. For example, Harder et al. (2014) used a beta-Poisson model for Norovirus, even though Teunis et al. (2008) recommended a hypergeometric model, and Messner et al. (2014) provided a simplification of the hypergeometric model in the form of a fractional Poisson model. Although the use of a more appropriate dose-response model by Harder et al. (2014) would have had a negligible influence on the results and conclusions, it appears worthwhile nevertheless to make sure that appropriate dose-response curves are selected and assumptions clarified.

Scaling of QMRA results to a functional unit

In LCA of urban water and sanitation systems, scaling to the functional unit usually takes place before impact assessment. This is possible because of the linearity of LCIA. Given the nonlinear mathematical relationships involved in QMRA, however, it makes little sense to scale pathogen emissions to a functional unit. In some of the case studies featuring concurrent use of QMRA and LCA, the functional unit of the LCA was therefore chosen so as to represent the full-scale emissions relevant for QMRA. For instance, the functional unit chosen by Aramaki et al. (2006) was the treatment of $50,000 \mathrm{~m}^{3}$ of wastewater per day during a year, and the functional unit chosen by Kobayashi et al. (2015a) was the provision of $18 \mathrm{GL}$ of reclaimed water per year. Both functional units represent full-scale plant operations during a year. Having the emission inventory based on full-scale plant operations is important (at least for pathogen emissions) because of the non-linear dose-response relationships for pathogens. Nevertheless, it would in principle be possible to scale the QMRA results to any other functional unit, as long as the QMRA itself is based on the full-scale emissions. However, some functional units may be more preferable than others (Harder et al. 2015a). One pitfall in particular is worth highlighting. Say QMRA model calculations are performed based on the full-scale operation of a water reuse facility, but the model results are scaled to a functional unit representing per capita water supply. Even if the units (a health burden per person) might suggest a health burden at the level of an individual, it actually is an average share of an aggregate health burden at the level of a population and through a range of different exposures.

\section{Coverage of pathogen emissions}

The three studies analysed in this paper only considered pathogen emissions from treatment operations (i.e. the "foreground system" in LCA terminology) but not from elsewhere in the supply chain that supports treatment operations (i.e. the "background system" in LCA terminology). Presenting the QMRA results covering only the foreground system in an LCA framework (as was the case in Heimersson et al. 2014 and Kobayashi et al. 2015) might camouflage the fact that the pathogen impact potential presented does not cover pathogen emissions in the background system.

In principle, it would be possible to cover pathogen emissions also in the background system, and also in the expanded system when system expansion is applied in LCA. System expansion is one way to facilitate comparison of alternatives with multiple functions in addition to the ones represented by the functional unit. For example, a treatment plant in a water reuse scenario might not only provide water but also wastewater treatment services as well as treatment residuals that can be used in soil improvement. An analyst may want to compare the environmental impacts of supplying $1 \mathrm{~m}^{3}$ of recycled water, or alternatively, water from a conventional surface water source. For a fair comparison, the environmental impacts of a separate system for the delivery of the same 
wastewater treatment services and soil improvement should be added to the environmental impacts of the conventional system. This procedure is called "system expansion" or "substitution" and is illustrated in Figure 4. The term system expansion means adding components to the system that does not supply as many functions as the multifunctional system, although the algebra of comparison is just as apt if the environmental burdens of the components are subtracted from the multifunctional system in the calculation.

However, pathogen emissions at different locations and points in time cannot be aggregated (and scaled to a functional unit) because of the non-linearity of dose-response models. Rather, emissions at different locations and points in time each require a separate QMRA, the results of which can very well be aggregated (and scaled to a functional unit). Having said the above, it is important to realise that the specific locations and points in time of emissions related to a specific product or service are not specified in LCA, and often cannot be specified due to the nature of the analysis. This hampers the consideration of pathogens in processes other than the core processes in the foreground system, unless the supply-chain is very well known and all the contributing processes can be located. In other words, it is difficult to model the health impact of pathogens in the background system.

Returning to the previous example, the comparison might look as follows. For the conventional surface water scenario, the estimation of the pathogen related health burden of the foreground system would encompass pathogen exposure through water consumption. For the recycled water scenario, the health burden would encompass pathogen exposure through water consumption as well as other exposure pathways such as recreational exposure to the wastewater effluent and agricultural application of the soil amendment. Hence, after consideration of the relative contributions for different exposure pathways (e.g. recreational exposure, consumption of agricultural produce), it may well be that just one dominates risk (e.g. Schoen et al. 2014), and only one needs to therefore be integrated with the LCA analysis. Following the LCA procedure for system expansion, the pathogen related health burden of the dominant exposure pathway(s) of the system expansion should be added to the conventional system or subtracted from the overall pathogen related health burden in the water-recycling scenario.

\section{Beyond static QMRA and attributional LCA?}

In this paper, the focus was on static QMRA, and the case studies that explored the concurrent use of QMRA and LCA all relied on static QMRA and attributional LCA. Nonetheless, the concurrent use of dynamic QMRA and LCA in principle should be possible as well. In a similar vein, it should in principle be possible to use QMRA results alongside consequential LCA. This means that there are ample opportunities for further case studies exploring these possibilities in more detail. In doing so, collaboration between LCA and QMRA experts would be helpful in order to ensure that in-depth knowledge and expertise from both fields is taken into account sufficiently.

\section{The importance of conscious design and clear communication}

The three case studies that explored the concurrent use of QMRA and LCA exhibited different ways to frame the concurrent use and relate QMRA and LCA results to one another. The intention here is neither to criticise any particular study, nor to judge which of the studies considered in this paper provided the most concise description of how QMRA and LCA results relate to one another. After all, in an emerging field that still is in the phase of exploring new opportunities, it is no surprise that a clear terminology and best practice have yet to fully emerge. The main intention here is to highlight the importance of consciously and carefully contemplating the use of terminology, and the way in which such studies are designed and results from QMRA and LCA presented. The 
341 conceptual model and discussion of issues to be aware of when concurrently using QMRA and LCA, as presented 342 in this paper, will hopefully facilitate more consistent design and more transparent communication of future case 343 studies assessing management options in urban water and sanitation infrastructures in terms of the broader adverse

344 effects of pathogens and other stressors on human health and the environment. Hopefully, this paper also inspired 345 QMRA experts to seize the opportunities to contribute to LCA method development.

\section{Acknowledgements}

347 Financial support from the Swedish Research Council for Environment, Agricultural Sciences and Spatial 348 Planning (FORMAS) under grant agreement No. 2012-1122 is gratefully acknowledged. 
Aramaki T, Galal M, Hanaki K (2006) Estimation of reduced and increasing health risks by installation of urban wastewater systems. Water Sci. Technol. 53(9):247-252

Amha YM, Kumaraswamy R, Ahmad F (2015) A probabilistic QMRA of Salmonella in direct agricultural reuse of treated municipal wastewater. Water Sci. Technol. 71(8):1203-1211

Ayuso-Gabella N, Page D, Masciopinto C, Aharoni A, Salgot M, Wintgens, T (2011) Quantifying the effect of managed aquifer recharge on the microbiological human health risks of irrigating crops with recycled water. Agr. Water Manage 99:93-102

Barker S, O’Toole J, Sinclair MI, Leder K, Malawaraarachchi M, Hamilton AJ (2013) A probabilistic model of Norovirus burden of disease associated with greywater irrigation of home-produced lettuce in Melbourne, Australia. Water Res. 47:1421-1432

Barker SF, Packer M, Scales PJ, Gray S, Snape I, Hamilton AJ (2013) Pathogen reduction requirements for direct potable reuse in Antarctica: Evaluating human health risks in small communities. Sci. Total Environ. 461-462:723-733

Baumann H, Tillman AM (2004) The Hitch Hiker's Guide to LCA. Studentlitteratur: Lund, Sweden.

Beaudequin D, Harden F, Roiko A, Stratton H, Lemckert C, Mengersen K (2015) Modelling microbial health risk of wastewater reuse: A systems perspective. Environ. Int. 84:131-141

Chen Z, Ngo HH, Guo W (2012) A critical review on sustainability assessment of recycled water schemes. Sci. Total Environ. 426:13-31

Eisenberg JN, Brookhart A, Rice G, Brown M, Colford JM Jr (2002) Disease transmission models for public health decision making: analysis of epidemic and endemic conditions caused by waterborne pathogens. Environ. Health Perspect. 110(8):783-790

Eisenberg JN, Soller JA, Scott J, Eisenberg DM, Colford JM Jr (2004) A dynamic model to assess microbial health risks associated with beneficial uses of biosolids. Risk Anal. 24(1):221-236

Eisenberg JN, Moore K, Soller JA, Eisenberg DM, Colford JM Jr (2008) Microbial risk assessment framework for exposure to amended sludge projects. Environ. Health Perspect. 116(6):727-733

Finnveden G, Hauschild MZ, Ekvall T, Guinée J, Heijungs R, Hellweg S, Koehler A, Pennington D, Suh S (2009) Recent developments in life cycle assessment. J. Environ. Manage. 91:1-21.

Forslund A, Ensink JHJ, Battilani A, Kljujev I, Gola S, Raicevic V, Jovanovic Z, Stikic R, Sandei L, Fletcher T, Dalsgaard A (2010) Faecal contamination and hygiene aspect associated with the use of treated wastewater and canal water for irrigation of potatoes (solanum tuberosum). Agr. Water Manage. 98:440-450

Gao T, Wang XC, Chen R, Hao Ngo H, Gue W (2015) Disability adjusted life year (DALY): A useful tool for quantitative assessment of environmental pollution. Sci. Tot. Environ. 511:268-287

García-Montoya M, Sengupta D, Nápoles-Rivera F, Ponce-Ortega JM, El-Halwagi, MM (2015) Environmental and economic analysis for the optimal reuse of water in a residential complex. Journal of Cleaner Production, DOI:10.1016/j.jclepro.2015.06.109 
Hajishengallis G, Darveau RP, Curtis MA (2012) The keystone-pathogen hypothesis. Nature Reviews Microbiology 10(10):717-725

Hamilton AJ, Stagnitti F, Kumarage SC, Premier RR (2007) RIRA: A tool for conducting health risk assessments for irrigation of edible crops with recycled water. Comput. Electron. Agr. 57:80-87

Harder R, Heimersson S, Svanström M, Peters GM (2014) Including pathogen risk in life cycle assessment of wastewater management - Part 1: Estimating the burden of disease associated with pathogens. Environ. Sci. Technol. 48(16):9338-9445

Harder R, Schoen M, Peters GM (2015a) Including pathogen risk in life cycle assessment of wastewater management. Implications for the choice of functional unit. Environ. Sci. Technol. 2015, 49 (1), 14-15

Harder R, Holmquist H, Molander S, Svanström M, Peters GM (2015b) Review of environmental assessment case studies blending elements of risk assessment and life cycle assessment. Environ. Sci. Technol. 49(22): 1308313093

Harder R, Peters GM, Molander S, Ashbolt NJ, Svanström M (2016) Including pathogen risk in life cycle assessment: the effect of modelling choices in the context of sewage sludge management. Int. J. Life Cycle Assess. 21(1): 60-69

Hauschild M, Goedkoop M, Guineé J, Heijungs R, Huijbregts M, Jolliet O, Margni M, De Schryver A, Humbert S, Laurent A, Sala S, Pant R (2013) Identifying best existing practice for characterization modeling in life cycle impact assessment. Int. J. Life Cycle Assess 18 (3):683-697Havelaar A, Melse JM (2003) Quantifying public health risk in the WHO Guidelines for drinking-water quality: A burden of disease approach. RIVM report 734301022. RIVM: Bilthoven.

Havelaar AH, van Duynhoven YTHP, Nauta MJ, Bouwknegt M, Heuvelink AE, de Wit GA, Nieuwenhuizen MGM, van de Kar NCA (2003) Disease burden in the Netherlands due to infections with Shiga-toxin producing Escherichia coli O157. RIVM report 284550008. RIVM: Bilthoven.

Havelaar AH, Swart AN (2014) Impact of acquired immunity and dose-dependent probability of illness on quantitative microbial risk assessment. Risk Anal. 34(10):1807-1819

Heimersson S, Harder R, Peters GM, Svanström M (2014) Including pathogen risk in life cycle assessment of wastewater management - Part 2: Quantitative comparison of potential impacts of pathogens to other impacts on human health. Environ. Sci. Technol. 48(16):9446-9453

Hendrickson TP, Nguyen MT, Sukardi M, Miot A, Horvath A, Nelson KL (2015) Life-cycle energy use and greenhouse gas emissions of a building-scale wastewater treatment and nonpotable reuse system. Environ. Sci. Technol. 49(17):10303-10311

Katukiza AY, Ronteltap M, van der Steen P, Foppen JWA, Lens PNL (2014) Quantification of microbial risks to human health caused by waterborne viruses and bacteria in an urban slum. J. Applied Microbiology 116:447463

Karlsson EK, Kwiatkowski DP, Sabeti PC (2014) Natural selection and infectious disease in human populations. Nature Reviews Genetics 15(6): 379-393 
Kemmeren JM, Mangen MJJ, van Duynhoven YTHP, Havelaar AH (2006) Priority Setting of Foodborne Pathogens: Disease Burden and Costs of Selected Enteric Pathogens. RIVM report 330080001. RIVM: Bilthoven.

Kobayashi Y, Peters GM, Ashbolt NJ, Heimersson S, Svanström M, Khan SJ (2015) Global and local health burden trade-off through the hybridisation of quantitative microbial risk assessment and life cycle assessment to aid water management. Water Res. 79:26-38

Kobayashi Y, Peters GM, Ashbolt NJ, Shiels S, Khan SJ (2015) Assessing burden of disease as disability adjusted life years in life cycle assessment. Sci. Total Environ. 530-531:120-128

Liu S, Persson KM (2014) Estimating microbial risk in treated wastewater for reuse: a case study in Lund, Sweden. J. Water Reuse Desalination 2014(4):263-275

Medema G, Loret JF, Stenström TA, Ashbolt NJ (2006) Quantitative Microbial Risk Assessment in the Water Safety Plan. Final Report on the EU MicroRisk Project. European Commission: Brussels.

Messner MJ, Berger P, Nappier SP (2014) Fractional Poisson: A simple dose-response model for human norovirus. Risk Anal. 34(10):1820-1829

Murray C (1994) Quantifying the burden of disease: The technical basis for disability-adjusted life years. B. World Health Organ. 72:429-445

Murray C, Lopez A (1996) Global burden of disease: A comprehensive assessment of mortality and disability from diseases, injuries, and risk factors in 1990 and projected to 2020. Global burden of disease and injury series, Vol. 1. Harvard School of Public Health, World Bank, World Health Organisation.

Nilsson P, Roser D, Thorwaldsdotter R, Petterson S, Davies C, Signor R, Bergstedt O, Ashbolt N (2007) SCADA data and the quantification of hazardous events for QMRA. J Wat Health 5:99-105

Petterson SR, Signor RS, Ashbolt NJ (2007) Incorporating method recovery uncertainties in stochastic estimates of raw water protozoan concentrations for QMRA. J Water Health 5(Suppl 1):51-65

Petterson SR, Stenström TA (2015) Quantification of pathogen inactivation efficacy by free chlorine disinfection of drinking water for QMRA. J Water Health 13(3):625-644

Sales-Ortells H, Medema G (2014) Screening-level microbial risk assessment of urban water locations: A tool for prioritization. Environ. Sci. Technol. 48(16):9780-9789

Sales-Ortells H, Medema G (2015) Microbial health risks associated with exposure to stormwater in a water plaza. Water Res. 74:34-46.

Schoen ME, Xue X, Hawkins TR, Ashbolt NJ (2014) Comparative human health risk analysis of coastal community water and waste service options. Environ. Sci. Technol. 48(16):9728-9736

Signor RS, Ashbolt NJ, Roser DJ (2007) Microbial risk implications of rainfall-induced runoff events entering a reservoir used as a drinking-water source. Journal of Water Supply: Research and Technology AQUA 56:515531

Soller JA (2009) The potential implications of person-to-person transmission of viral infection for US EPA's Groundwater Rule. J. Water Health 7(2):208-223 
Symonds E, Verbyla ME, Lukasik JO, Kafle RC, Breitbart M, Mihelcic JR (2014) A case study of enteric virus removal and insights into the associated risk of water reuse for two wastewater treatment pond systems in Bolivia. Water Res. 65:257-270

Teunis PF, Moe CL, Liu P, Miller SE, Lindesmith L, Baric RS, Le Pendu J, Calderon RL (2008) Norwalk virus: How infectious is it? J. Medical Virology 80(8):1468-1476

Vijgen S, Mangen M, Kortbeek L, van Duijnhoven Y, Havelaar A (2007) Disease Burden and Related Costs of Cryptosporidiosis and Giardiasis in the Netherlands. RIVM report 330081001. RIVM: Bilthoven.

Waters EK, Hamilton AJ, Sidhu HS, Sidhu LA, Dunbar M (2016) Zoonotic transmission of waterborne disease: A mathematical model. Bull. Math. Biol. 78:169-183

Westrell T, Bergstedt O, Stenstrom TA, Ashbolt N (2003) A theoretical approach to assess microbial risks due to failures in drinking water systems. Int. J. Environ. Health Res. 13(2):181-197

WHO (2006) Guidelines for the Safe Use of Wastewater, Excreta and Greywater. Volume 1 Policy and regulatory aspects, World Health Organization, Geneva.

Xue X, Schoen ME, Ma XC, Hawkins TR, Ashbolt N, Cashdollar J, Garland J (2015) Critical insights for a sustainability framework to address integrated community water services: Technical metrics and approaches. Water Res. 77:155-169.

Xue X, Hawkins TR, Schoen ME, Garland J and Ashbolt NJ (2016) Comparing the life cycle energy consumption, global warming and eutrophication potentials of several water and waste service options. Water $8(4)$, w8040154. 


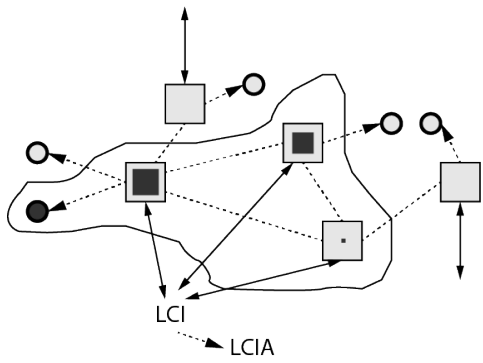

Product under consideration

Other products

Process in the global

supply chain network

Share of resource use and

- emissions partitioned to the product under consideration

4 Resource use and emissions

$\checkmark$ of a given process

os Product system

477 Fig. 1 Visual summary of LCA. Broadly speaking, the task of a LCA study is to identify the resource use and 478 emissions of the (current or future) global supply system that are related to the product system under consideration 479 (LCI). Resource use and emissions are then translated into potential environmental impacts (LCIA).

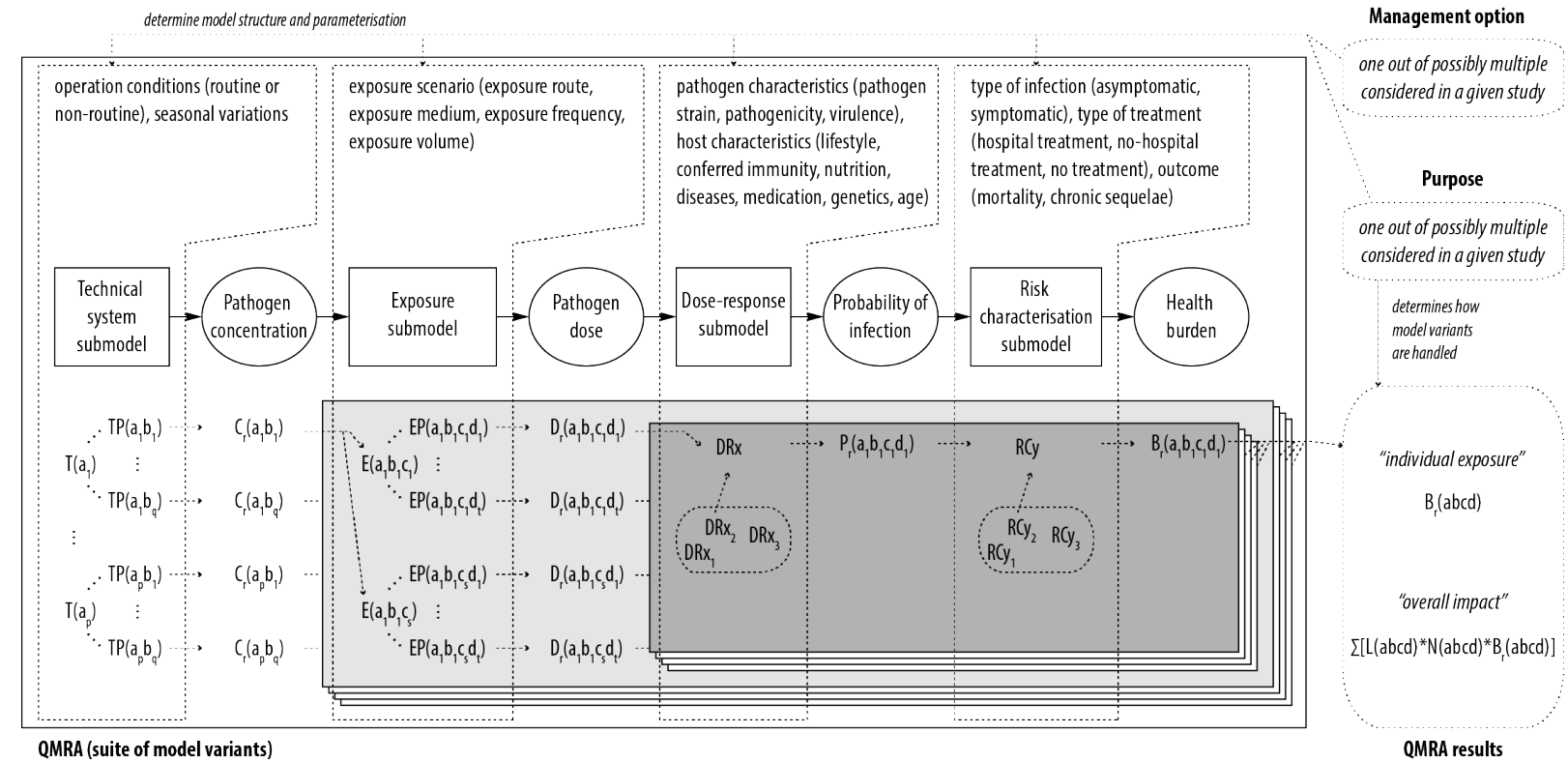

Fig. 2 Conceptual model for the assessment of human health risks associated with pathogens. The conceptual model consists of four sub-models and represents one possible out of multiple water reuse scenarios considered in a given case study. The sub-models and the parameters influencing the sub-models are based on Beaudequin et al. (2015). Given the different possible parameterisations of each sub-model, each QMRA in principle consists of a suite of model variants, where each model variant represents different parameterisations of the four sub-models. T $=$ technical system scenario (a), TP = technical system scenario parameterisation (b), $\mathrm{E}=$ exposure scenario (c), $\mathrm{EP}=$ exposure scenario parameterisation $(\mathrm{d}), \mathrm{DR}=$ dose-response relationship, $\mathrm{P}=$ probability of infection, $\mathrm{RC}=$ risk characterisation relationship, $\mathrm{B}=$ health burden, $\mathrm{L}=$ likelihood of model variant, $\mathrm{N}=$ number of people exposed in model variant. Note that every pathogen considered (r) needs separate treatment and parameterisation. 


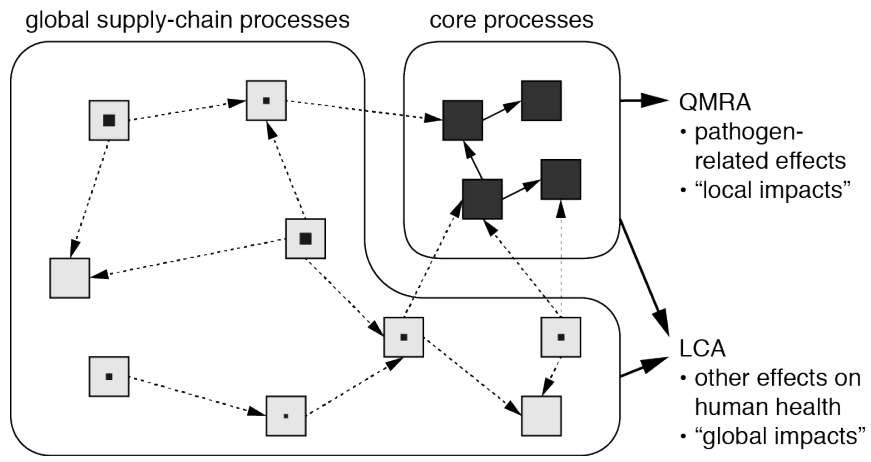

491 Fig. 3 Overall model structure of the three case studies analysed in this paper. QMRA models are used to estimate 492 the pathogen-related health burden for a number of core processes. LCA is used to estimate the health burden related to other stressors for both the core processes and the supply-chain processes based on LCIA models.
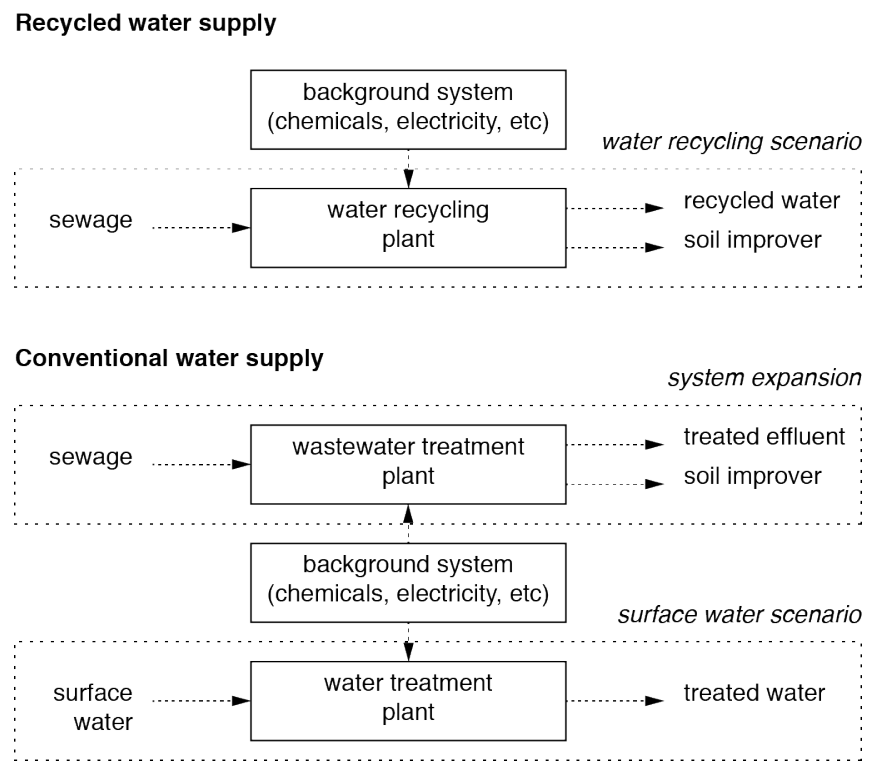

495 Fig. 4 System expansion exemplified for two water supply scenarios: conventional water supply and water 496 recycling. Details are provided in the text. 
Table 1 Use of different assessment endpoints (top row) in relation to different assessment purposes (left column).

\begin{tabular}{llll}
\hline QMRA purpose & $\begin{array}{l}\text { Probability of infection } \\
\text { or illness (Pinf, Pill) }\end{array}$ & $\begin{array}{l}\text { Number of cases of infection } \\
\text { or illness (Ninf, Nill) }\end{array}$ & Health burden (B) \\
\hline Threshold comparison & Useful & Useful & Useful \\
$\begin{array}{l}\text { Comparison among different } \\
\text { exposures }\end{array}$ & $\begin{array}{l}\text { Useful for similar health } \\
\text { outcomes }\end{array}$ & $\begin{array}{l}\text { Useful for similar health } \\
\text { outcomes }\end{array}$ & $\begin{array}{l}\text { Useful for similar } \\
\text { and different health } \\
\text { outcomes }\end{array}$ \\
$\begin{array}{l}\text { Comparison among different } \\
\text { management options }\end{array}$ & $\begin{array}{l}\text { Useful for similar health } \\
\text { outcomes }\end{array}$ & $\begin{array}{l}\text { Useful for similar health } \\
\text { outcomes }\end{array}$ & $\begin{array}{l}\text { Useful for similar } \\
\text { and different health } \\
\text { outcomes }\end{array}$ \\
\hline
\end{tabular}

